\title{
Aplicación de la Legislación Canónica en la América Latina
}

\author{
Por el Excmo. Monseñor Dr. JOSE DAMMERT BELLIDO
}

Hace años, quizá desde el Seminario al estudiar las normas canónicas $Y$ vislumbrar la dura realidad de las parroquias andinas, presentia que muchas de ellas en diversas ocasiones, no eran aplicables en nuestros paises.

Más tarde al conversar con párrocos de alejados pueblos, y en la actividad de vicario general de la arquidiócesis de Lima, percibí con mayor nitidez algunos de los agudos problemas que angustiaban la conciencia de los sacerdotes en la sierra -en especial de los últimamente ordenados-. y escuché la observación de un experimentado misionero redentorista que "arriba de los dos mil metros no rige el Derecho canónico".

La toma de posesión de una apartada diócesis y el contacto directo con todos los sacerdotes de ella nos ha hecho palpar la realidad. El primor impacto recibido fue al promulgar el indulto de la S. C. de Ritos a los Ordinarios del Perú que concede diversas facultades, ya otorgadas por "Fropaganda Fide" a los territorios de misión: no se trataba de nuevas concesiones en muchos casos, sino de regularizar legalmente prácticas habituales hacía mucho tiempo, pues por la situación extraordinaria en que se desarrolla el ministerio pastoral en estas regiones, obligaba a aplicarlas de hecho. Lo mismo al poner en conocimiento el último indulto de la misma $\mathbf{S}$. Congregación a los Ordinarios del C.E.L.A.M. sobre administración del bautismo a cinco párvulos o más simultáneamente, un celoso párroco me advirtió sonriendo "acabo de aplicarlo en la celebración de la fiesta de un pueblo, porque los bautizos se hacen por decenas".

Es lástima que las prescripciones de los antiguos y sabios "Concilios limenses" del siglo XVI cayeran en desuso por el deseo de uniformarse a las disposiciones generales de la Iglesia latina. Así en el "Concilio Plenario latinoamericano" de 1899 se dejaron de lado sagaces costumbres adaptadas a la mentalidad de estos pueblos; algunas se conservaron mediante las "trentenales" de León XIII, renovadas por las "decenales" para América latina y muy pocas. El Código pianobenedictino imprimió mayor uniformidad en el nombre $y$ en la apariencia, pero diversas normas son impracticables; ni siquiera en las grandes arquidiócesis de este continente pueden aplicarse estrictamente las normas canónicas. 
Paso a exponer algunos de las ejemplos ce mayor relieve.

PARROQUIAS.-Los exiensos y poblcicios territorios que actualmente se denominan parroquias no responcen a la noción canónica. Préeribie es darles su antiguo nombre "doctrinas". Ccoda cura estaba encargado de catequizar a los indígenas y por eso recibion el nombre de "doctrineros o curas de la doctrina"; la cenominación de pórrocos estaba reservaco en las ciudades a la cura de almas de los e:spañoles.

Al uniformar la legislación han recibido el nombre de parroquias. En la carta que la Secretaría de Estado dirigió a la semana social canadiense de 1953 se dice que "la parroquia es hogar de vida religiosa $\mathrm{y}$ de expansión misionera", "célula verdaderamente viviente y activa del Cuerpo de Cristo", "comunidad en torno a la fe, la oración y la caridad" y "es la primera comunidad de vida cristiana en la Iglesia de Jesucristo" 1 . Todos estos hermosos conceptos no se encuentran en nuestras "parroquias". que en realidad se reducen a centros de administración del sacramento del bautismo, $y \in n$ menor escala del matrimonio, confesión y eucaristía; a la expedición de partidas de los registros parroquiales - debido a la manifiesta insuficiencia de los registros civiles-; a la celebración de misas, cantadas y vigilicics, de cifuntos; y a la celebración de las fiestas de los san.tos en pueblos y caseríos, con las consabidas procesiones y escasa o nula catequización. Cada una de estas parroquias tiene un promedio de 20,000 habitantes - varias muchos más- diseminados en las escabrosas y dilatadas serranías de los Andes: "pero también será un obstáculo para el buen gobiemo pastoral la excesiva concentración demográfica o la amplitud de la extensión parroquial. No hay pastoral parroquial verdadera si la parroquia no es de talla humana $(4,000$ a 5,000 habitantes señalan los sociólogos)"i:.

¿Es posible aplicar en esas parroquias las prescripciones del Código de Derecho canónico?

a) Ley de residencia.-El Cóaligo la impone con severas sanciones, lo cual es justo: sin embargo, ¿puede ser estrictamente exigida a los párrocos de las campiñas latinoamericanas?

En su última pastoral de cuajesma, el primer cardenal peruano, Arzobispo Guevara, describe con términos precisos la situación: "Ya podéis suponer cuál será la tragedia de orden espiritual en la que se debaten los infelices feligreses de esas parroquias abandonadas, no por incuria de la autoridad eclesićatica por cierto, sino por la conocida escasez de sacerdotes que aflige a toảas las diócesis del Perú.

"Pensar que para el remedio de esta necesidad urgente, bastaría enviar uno que otro sacerdote, es provocar un nuevo conflicto, sobre el cual, amados hijos, os llamamos seriamente la atención.

"El problema a que hacemos referencia lo constituye el hecho evi-

1 Citada por C. FLORISTAN: La parroquá, comunidad eucarística (Madrid, 196l), página 99. Al leer este hermoso ensayo en la diócesis de Cajamarca se vislumbra un ideal que se alcanzará en estas tierras sólo después de varios siglos.

2 FLORISTAN: Ob. Cit. p. 117. 
dente de que un solo sacerdote, humanamente hablando, no puede atender a esas parroquias compuestas por muchos pueblos anexos, separados unos de otros par largas distancias, que se comunican por caminos escabrosos que ofrecen muchos peligros para la misma vida.

"Además es pecaminoso, por cuanto el párroco aislado, en un centro social deprimente, carece de los medios ordinarios de santificación y se encuentra rodeado de ocasiones próximas necesarias de pecado, sin estímulo natural de ninguna especie.

"Lo calificamos asimismo de contrario a las luces de la razón porque ésta prohibe adoptar medios que ciertamente no conducen al fin propuesto como lo demuestra la experiencia. Por último es contrario a las luces de la fe, pues ésta nos enseña que la asistencia o intervención extraordinaria de que Dios suele valerse para bien y enseñanza de los hombres, no debe suponérsela como base de gobierno y administración, sobre todo, si se omiten otros medios extraordinarios factibles y señalados por el mismo Dios.

"Fácilmente se comprende que un sacerdote rodeado de circunstancias tan poco favorables para su conservación espiritual y moral, caeró en el abismo del vicio. Para evitar estos escollos tan graves es necesario ser un héroe y los héroes no se improvisan, no se engendran a cada paso. La hcroicidad es un hecho esporádico que va más allá, que supera a lo común Y ordinario"s.

En tales circunstancias es imposible exigir a nuestros párrocos en forma severa la residencia canónica, y en cuanto a los sacerdotes jóvenes no enviarlos solos de ninguna manera, sino tender - dentro de las posibilidades numéricas de clero- a constituir las llamadas parroquias comunitarias.

Debe permitirse a los párrocos que con la mavor frecuencia viajen a las ciudades para atender sus necesidades espirituales y aun materiales.

b) Instrucción catequística.-El canon 1329 prescribe que es deber propio y gravísimo de los pastores de almas. En cambio en América latina los párrocos cumplen al pie de la letra las instrucciones dadas por San Vicente de Paúl a uno de los primeros misioneros de Madagascar: "Cuando haváis llegado a la isla, os tendréis que arreglar como podáis"4.

En la sede parroquial se procura con la ayuda de los maestros, en particular de las maestras, y de algunas mujeres piadosas organizar los catecismos, como buenamente se puede. De hecho, a pesar de las instan. cias de los Dicasterios Romanos, de las Ásambleas Episcopales y aun de los Sínodos diocesanos, en muy pocas diócesis existe la Congregación de la Doctrina Cristiana, no por falta de buena voluntad, sino de tiempo. Generclmente el párroco tiene a su cargo treinta o más anexos, sean aldeas, caseríos o haciendas, y a pedido de sus habitantes los visita una vez al año para celebrar la fiesta del Patrón, permaneciendo breves días. En ese corto lapso prepara a los niños para la primera comunión, confiesa a los alumnos de las escuelas y a las personas devotas; bautiza a los niños na-

3 En "El Amigo del Clero", órgano oficial del Arzobispado de Lima, vol. 63 (1954). páginas 61-62.

4 Citado por J. CALVET: San Vicente de Paul (Buenos Aires, 1950), p. 202. 
cidos durante el año (hace pocos días en un pueblo hubo en dos o tres días más de 170 bautizos). ¿En qué momento se organiza la catequésis?

Urge el restablecimiento de escuelas permanentes para catequistas, pero - aparte de los problemas económicos de sostenimiento- se escuentra uno con la falta de sacerdotes para dirigirlas y luego para vigilar la labor de los catequistas.

Además como 400 años de cristianismo no pasan en vano, el sacerdote debe forzosamente atender una serie de prácticas religiosas (procesiones, bendiciones, novenas, triduos, etc.) que exige el pueblo cristiano, y que es casi lo único que alimenta su fe. No se trata de misiones entre infieles, en las que se puede comenzar según el juicio de cada misionero, sino que existe una tradición o costumbres tradicionales que no pueden cortarse de golpe.

c) Matrimonio.-En estas circunstancias la celebración de matrimonios debe hacerse "more missionum", con dispensa de proclamas y muchas veces de presentación de partidas bautismales, pues los contrayentes pertenecen a pueblos lejanos y de difícil acceso o porque, debido a la abundancia de bautizos no se les inscribió. Por lo general se trata de legalizar uniones de varios años; los campesinos comienzan las relaciones conyugales a los dieciséis o diecisiete años los varones y catorce o quince las mujeres, sin bendición sacramental ni aprobación civil.

Un grave perjuicio causa a estas uniones puramente naturales $-\mathrm{y}$ en su gran mayoría monógamas- el servicio militar que arranca al hombre de su hogar, dejando mujer y dos o tres hijos; al ser licenciados del ejército o no regresa, porque las condiciones de vida y de trabajo son mejores en la costa que en las superpobladas regiones andinas, o regresa con una instrucción sexual mal impartida en el ejército. La primitiva unión se destruye, creciendo los niños faltos de vigilancia paterna.

La promiscuidad no es tan grave como en ciertas poblaciones amazónicas", pero todavía está vigente la admonición del más ilustre obispo del Perú en el siglo XVIII, don Baltasar Jaime Martínez de Compañón, a un cura de su extensa diócesis de Trujillo, que lamentaba los incestos frecuentes en un pueblo: "primero provean el señor Cura y las autoridades civiles a la construcción de casas adecuadas con tres habitaciones para los esposos, hijos varones e hijas mujeres, y luego se les instruya para posteriormente aplicar las penas canónicas".

Ante estas dificultades familiares se comprende la escasez de vocaciones eclesiásticas por la carencia de vida sacramental, de una auténtica vida familiar, y el gran número de hijos naturales.

d) Cumplimiento del precepto dominical.-Dado que los párrocos deben cumplir su ministerio en diferentes pueblos, con frecuencia sucede que en los domingos y días de precepto no está en la cabecera de parroquia $y$ los fieles se quedan sin escuchar misa. De otra parte en los caseríos y haciendas - como se ha señalado- el sacerdote llega una vez al

5Ver J. M. VAZQUEZ, O. P., PUCALLPA: Estudio socio-religioso do una ciudad del Perú (Madrid, 1962), p. 185 y sgs. 
año y los pobladores trabajan en esos días pues no tienen costumbre de celebrarlos y cuando se trasladan a vivir a las ciudades es casi imposible que comprendan la obligación de cumplir con el precepto dominical.

Respecto a la asistencia a misa el mismo obispo Martínez de Compañón ante la denuncia que los moradores de un caserío no concurrían $\alpha$ la misa en la sede parroquial, dispuso que el señor Cura construyera, a sus expensas, un puente sobre un riachuelo para que pudieran pasar con comodidad $\mathrm{y}$ sin peligro.

Para facilitar este cumplimiento debe estudiarse la posibilidad que se satisfaga escuchando misa a partir de las vísperas del sábado o de las primeras vísperas de la fiesta, dado que el oficio dominical o festivo comienza con esas vísperas ("Novus Codex Rubricarum" núm. 5 y 13). Por la escasez de sacerdotes sería posible con una misa vespertina atender a pueblos, que no pueden contar con la misa dominical ni con el indulto de trinación.

e) Cumplimiento del precepto pascual.-Se ha de aconsejar a los fieles que satisfagan a este precepto cada uno en su parroquia (cn. 859 par. 3). Gracias a Dios por indulto apostólico en el Perú puede cumplirse desde Septuagésima hasta el 10 de noviembre, con lo que se favorece a los pobladores de aldeas que sólo ven al sacerdote una vez al año, pero sería preferible poder extender ese beneficio a todo el año, porque los pueblos que tienen como patrono a la Inmaculada Concepción, al Niño Jesús، a los Magos o San Sebastián, sólo podrán hacerlo en esas festividades.

f) Recitación del oficio divino.-El exceso de trabajo ministerial en América latina en los días domingo de precepto y en las solemnidades de los Patronos por las confesiones, bautismos, celebración de dos o tres misas con homilía o panegírico, y por los viajes - a pie o a caballo- de una población $a$ otra, imposibilitan la recitación del oficio divino o, por lo menos, en forma atenta y devota, debido a la consiguiente fatiga natural.

Es indispensable una reducción para aquellos sacerdotes que por atención a las almas están en las condiciones expuestas, al menos de las horas menores, y de las Vísperas que serían conmutadas por la Misa vespertina.

También se podría proponer que los obligados al oficio divino satisfagan su obligación para Maitines con la recitación solemne del nocturno del oficio votivo de difuntos en las exequias, a semejanza de la conmutación del oficio en la vigilia de la dedicación de una iglesia (Novus Codex Rubricarum, Variatiores n. 60).

g) Ajeno al estado clerical es el ejercicio de la medicina.- En estas regiones debe formarse la conciencia que estamos en tierra de misiones. En los pueblos no hay médicos, y muchas veces ni enfermeros o sanitarios. El párroco comienza por regalar algunas medicinas, poner inyecciones, curar heridas leves, y termina en atender casos más graves, pues la guardia civil lleva a los heridos al cura para que los atienda o en los hospitales urbanos se recomienda al enfermo, una vez operado, que lo siga viendo el "Padrecito" de su pueblo para que no tenga que viajar tanto; también algún Prelado nullius personalmente ha debido en la visita pas. toral atender a los enfermos. 
DIOCESIS. a) Relaciones quinquenales,-Los formularios de las relaciones quinquenales que se remiten a las Sagradas Congregaciones Romanas sobre catequesis, educación, seminarios, procesos matrimoniales, $y$ aun la misma relación que se une a la visita "ad límina" no reflejan la realidad de las diócesis latinoamericanas. Se trata de formularios o encuestas redactadas para Europa y aquí se contestan a la buena, procurando adaptarse con respuestas vagas o con decisiones que quedan en el papel. Un santo Nuncio, el recordado monseñor Arrigoni, me decía que los cuadros de la Ācción Católica diocesana eran designados únicamente para darle gusto al Representante del Papa.

Con frecuencia las llamadas comisiones o juntas diocesanas son nombradas con ocasión de la relación quinquenal, pero nunca se reúnen. Otras veces ni siquiera existen por la carencia de personal. Sin 'zmbargo, el prurito de redactar reglamentos totalmente conforme a la legislación general es tan grande, que acaban de aprobarse unos estatutos para la "Unión misional del Clero en el Perú", tan distantes de nuestra realidad, que no tendrán aplicación en ninguna circunscripción eclesiástica de la nación.

b) Ceremonial de Obispos.--Aparte de su urgente y necesaria revisión para suprimir exterioridades supérfluas acordes con el Renacimiento - con Versalles, en América latina se exige-por razones de índole pastoral- que las cerəmonias pontificiales sean simplificadas. En primer lugar el rito de la Confirmación debe ser modificado pues en las visitas pastorales fácilmente se pasa el millar de confirmados en cada pueblo. Luego reducir al mínimo la presencia de ministros sagrados, principalmente en las grandes celebraciones del Triduo Sacro y del Corpus Christi, aunque parezca que el Obispo debe estar rodeado de su presbiterio. En nuestros países la devoción de los fieles hacia estos días sagrados es muy grande, y aprovechan de confesar y comulgar; en algunos pueblos han sido suprimidas las fiestas patronales por imposición de autoridades poco cristianas, pero por presión popular la celebración de la Semana Santa ha persistido. Los fundamentos del catolicismo en América latina son el culto eucarístico, la devoción mariana y la compenetración con la Pasión del Señor. Entonces es preferible que los sacerdotes atiendan las numerosas confesiones y celebren la Semana Santa en aquellos pueblos que ordinariamente carecen de párroco a que asistan al Obispo para dar mayor realce a los ritos pontificales.

c) Curias diocesanas.-La labor administrativa es muy reducida por el número de sacerdotes: lo triste es atender a las delegaciones de pueblos que hace treinta años están privados de la asistencia permanente del sacerdote, y no se les puede complacer.

La labor más fuerte en las curias peruanas se refiere a la inscripción o rectificación de partidas bautismales. Como los registros civiles no funcionon eficientemente, para obtener documentos de identidad ( $v$. g., para matrícula en las escuelas, inscripción en los registros militar y electoral - aun para sacar pasaporte) los fieles piden su partida de bautismo. Debido a la administración de los bautizos en forma masiva, como se ha indicado anteriormente, al abandono de los archivos parroquiales por falta de párroco, muchas veces no aparecen inscritos o con datos erróneos. Por la 
frecuencia de estos casos el VIII Concilio Provincial limense de 1928, turo que dar normas específicas para el asentamiento judicial de partidas y su rectificación.

LITURGIA. a) Cambio de estaciones.-Para las naciones del hemisferio meridional debe tenerse presente el cambio de estaciones respecto al año litúrgico. Es necesario dejar al criterio del Ordinario o de la Conferencia Episcopal la posibilidad de trasladar las prácticas penitenciales de Cuaresma - tal vez al Adviento- porque el tiempo cuaresmal coincide con el verano, las vacaciones escolares, etc., a semejanza de la facultad otorgada para las Rogaciones (Novus Codex Rubricarum, Variationes n. 27).

Por el mismo motivo debe concederse a los Ordinarios la facultad para cutorizar la celebración de la Misa de medianoche en la Navidad del Señor en cualquier iglesia u oratorio público y semi-público, pues el clima templado o cálido invita a todos los feligreses a salir de sus hogares $y$ concurrir a los templos. Lo mismo se expresa para la costumbre -introducida en los últimos años y muy bien acogida por los fieles- de celebrar el Santo Sacrificio en la medianoche del 31 de diciembre.

Al acentuar la liturgia el carácter primaveral de las Pascuas de Resurrección ("Florida") y de Pentecostés ("de las Rosas"), no se aviene con el otoño en que se celebran en estas naciones.

b) Altar.-La exigencia que el altar o piedra de ara encierre reliquias de mártires ocasionaba serias dificultades para la celebración de la Misa, porque en los pueblos o caserios apartados se encontraban profanados, debido a cierta modalidad superticiosa que para curar enfermedades era necesario beber líquidos que contuvieran reliquias. Los caminos escabrosos en otras oportunidades destrozaban las piedras de ara que llevaba el sacerdote. Gracias a la bənignidad dei Santo Padre Juan XXIII, en la renovación de las "Facultades decenales", se ha concedido el uso de "corporales con reliquias", y en la novísima edición de la II parte del Pontifi. cal romano se ha agregado la "Benedictio antimensium". Así ha sido resuelta una grave dificultad que parecia insalvable.

c) Música-En conformidad a las disposiciones pontificias que reno. varon la música sagrada a partir de San Pio $\mathrm{X}$ en los seminarios, se enseña el canto gregoriano y polifónico. La belleza de las modulaciones gregoriancis para quien ha aprendido desde su infancia a amar y admirar la vida benedictina, es sentida fuertemente y eleva nuestros espíritus, lo mismo que las hermosas composiciones polifónicas. Pero al salir del seminario y dispersarse por las inmensas soledades de nuestras parroquias desaparece hasta el eco de tan bellas melodías, pues ni se vuelven a escuchar ni se puede practicar lo aprendido.

Se trató de estạblecer las vísperas dominicales $y$ enseñar $\alpha$ los fieles la misa "de angelis", sin logar penetrar en la masa. Ahora se insiste mucho en las denominadas "misas comunitarias" y en los salmos de Gelineau, que lentamente penetran en los colegios de las ciudades.

En cambio, los campesinos de habla castellana tienen viejos cónticos al Santísimo y a la Virgen, lo mismo que para acompañar los entierros, que persisten al margen del clero.

La gran población indígena -quechua y aimará- de los Andes del 
Ecuador, Perú y Bolivia, posee hermosos cánticos en su lengua con melodías propias, que inciden vivamente en las profundidades religiosas del alma indígena, insensible a la música occidental.

Un testigo, no católico, observa: "Afirmamos que el conjunto de himnos, oraciones y parábolas quechuas católicos pertenecen a la literatura quechua con tanta propiedad como los cantos y mitos folklóricos. Hace $\alpha-$ penas veinte días que escuché en el templo de La Soledad, de Huaraz, un coro de quinientos indios entonando un antiquísimo himno católico quechua. Guiaban el coro dos cantores indígenas clásicos; uno de ellos leía el himno en un voluminoso $y$ viejísimo cuaderno... Los dos cantores entonaban el himno y la multitud repetía la estrofa. Algunas de las mujeres que estaban arrodilladas cerca de los cantores se inclinaban, y permanecían llorando mientras los cantores entonaban las estrofas; cuando el coro empezaba, ellas se erguían levantando los brazos y cantaban con voz entrecortada...

"Muchos himnos y oraciones son traducciones del castellano. Pero quisiéramos hacer resaltar el ejemplar acierto, el sorprendente criterio estético que inspiró a sus traductores. Se trata de verdaderas conversiones de poesías religiosas castellanas en otras quechuas no sólo equivalentes sino, en todos los casos posibles, más intensas e influyentes. Esta superación es posible, porque el quechua es, por su propia naturaleza, un medio de expresión más íntimo, más cargado de símbolo y de aliento, para la traducción de algunos sentimientos humanos que son predominantes y caracterís. ticos de los pueblos agrícolas; tal la ternura: himnos al Niño Jesús, a Ia Virgen, al Cristo crucificado y sangrante; himnos de gratitud o de imploración; oración del amanecer, cantos para aplacar la ira de los elementos...

"Las traducciones y los himnos y oraciones originales quechua; fue.-. ron creadas con una legitimidad tan absoluta como la literatura folklórica. La mayor prueba de tal originalidad está en su actual vigencia. Es posible, que los himnos y oraciones hayan sufrido readaptación y cambios en el lenguaje $y$ en el contenido, pues su folklorización ha sido y es progresiva; pero entre ellos existen muchos de estilo arcaico, en los cuales el quechua antiguo, el que podemos llamar clásico, resplandece.

"La conservación de los himnos ha sido posible, además, gracias a otro de los fundamentales aciertos de la catequización primitiva. El método de los misioneros... estuvo asombrosamente inspirado en el conocimiento de la psicología indígena; la audacia de la obra misional se explica únicamente por este dominio de la cultura nativa. Parece evidente que los misioneros compusieron los himnos católicos adaptándolos a los géneros más adecuados de la propia música indígena... Será necesario realizar una investigación musicológica de ellos, pero podemos afirmar que la mayor parte... es de música india antigua. Los coros que hemos oído en los pueblos andinos y el que hace poco escuchamos en Huaraz, es de música indígena. Nuestra afirmación es subjetiva, pero tiene el fundamento de que conocemos la cultura india por haber nacido en ella.

"La música del coro que escuchamos en Huaraz era una especie de yarahui funerario... Cada estrofa era cantada con la misma melodía. El coro contestaba a los guías o solistas repitiendo cada estrofa. Sin em- 
bargo, la monótona repetición del lento y angustioso yarahui creaba en el templo un contagioso ambiente de lacerante imploración, de lamento. Lloraban las mujeres, unas como ya descrito, con muchos aspavientos, teatralmente; otras, cubriéndose con sus negras mantas. ¿No era éste el efecto. que deseaba provocar el autor del himno? Allí, en el templo, bajo la influencia liberadora de la música y de la poesía, en un público lugar, podían descargar los desventurados indios todo el peso de su dolor, quejarse y llorar a mares; para luego salir consolados a trabajar y a vivir, siempre metidos en su hondo círculo, vueltos sobre sí mismos, culturalmente diferenciados, rodando hasta la hora en que este dualismo con que se enfrentaban a la otra cultura, tendría que ser resuelto" 6.

También debe tenerse en cuenta la influencia africana en el Brasil, Centroamérica, las Antillas y las costas de Venezuela, Colombia y Perú, y en particular en los "negro spirituals" del sur de los Estados Unidos, con innegable fondo $y$ sentido religioso.

SEMINARIOS.- $\alpha$ ) Edad.-En el "Index rerum" del "Enchiridion Clericorum" (Roma, 1938), bajo la voz "aetas", se encuentran los testimonios de la tradición eclesiástica que se resumen en el $\mathrm{cn} .972$ par. 1 "curandum ut ad sacros adspirantes inde a teneris annis in Seminario recipiantur", lo que ha influído, a veces en forma casi exclusiva, a que el ingreso en los seminarios o postulantados religiosos se reserve a los niños entre 12 y 16 años y la formación que se imparta en ellos sea adecuada a dicha edad.

Entre los campesinos de esta diócesis, por las dificultades provenientes de la distancia del hogar a la escuela, la urgencia de ayudar a los padres en las faenas pastoriles o agrícolas, es bastante común que los muchachos concluyan la instrucción primaria a los 16 o 17 años, edad en que en las ciudades se está por terminar la educación secundaria.

Esto determina que en los Seminarios destinados a las diócesis, con prevalencia de población rural, se requiera un fuerte sentido de adaptación de las normas e instrucciones que rigen en los seminarios, ya que no se trata de formar a niños, sino a adolescentes que conocen los duros trabajos del campo y cuyos coetáneos inician la vida conyugal son su joven compañera. Los métodos pedagógicos deben forzosamente variar para obtener la sólida formación de estos aspirantes al sacerdocio: debe advertirse que muchos abnegados y celosos sacerdotes han ingresado en tales condiciones al seminario.

b) Latín.-Punto crucial en estos momentos. Reconozco sinceramente las ventajas que señala para su uso como lengua oficial de la Iglesia y como medio insustituible de formación e investigación Mons. Dino Staffá $^{\top}$. pues he estudiado varios años en Europa y por muchos más me he dedicado a la enseñanza del Derecho romano. Por eso coincido con el'

6 I. M. ARGUEDAS: La literatura quechua en el Perú, en la revista "Mar del Sur", volumen I (Lima), págs. 47-49.

7 La unidad de la fe y la unificación de los pueblos en el magisterio del Sumo Pontífice Juan XXIII (Roma, 1961), págs. 30-32. 
ilustre Prelado en que "no deje nunca de ser posesión de sus sacerdotes, los cuales, mediante la lengua, que es suya, su gloria, llave de la tradición y de la ciencia sagrada, puedan llegar directamente a las fuentes de la doctrina católica, habituarse al uso necesario de una terminología exacta, común, inmutable", pero frente a las severas y rígidas "Ordinationes ad Constitutionem Veterum sapientia rite exsequendam", de 22 de abril de 1962 (A. A. S., vol. 44, p. 339 y sgs.), temo seriamente por el futuro vocacional en América latina.

En nuestros países hace muchos años que el latín ha sido excluido de las escuelas, tanto estatales como particulares, y se ha formado -por decir así- un serio complejo frente a su aprendizaje, que popularmente se traduce en la expresión "es un latín" cuando se tropieza con algo incomprensible. Los profesores de nuestros seminarios luchan denodadamente para concluir con esta dificultad $y$ obtienen en muchas ocasiones busnos resultados; mas en la mayoría tienen que satisfacerse con que entiendan sin atreverse a profundizar más.

Además, no sólo entre los seminaristas provenientes del habla quechua o cimará, es muy deficiente el conocimiento del castellano, sino, en general, entre todos los estudiantes; esto se debe a la deficiente preparación recibida en la escuela primaria por la penuria de buenos maestros y el exceso de alumnado. Antes de insistir en el latín debe afianzarse el estudio de la lengua castellana: se alargan los estudios por este motivo, se prolongan más para obtener conocimiento perfecto del latin y mientras tanto nuestros campzsinos permanecen sumidos en la ignorancia religiosa $y$ abandonados a su propia suerte porque las disertaciones académiccs deben ser dichas en latín ciceroniano.

He señalado más arriba que muchos jóvenes ingresan al seminario menor a los 17 años porque acaban de terminar su instrucción primaria; lo mismo las llamadas vocaciones "maduras o adultas y tardías", ante una exigencia tan severa en la enseñanza del latín y el alargarse de los estudios, se echarán atrás al temer no aprenderlo en forma perfecta. En cambio palpamos el celo apostólico que despliegan y al mismo tiempo el abandono espiritual de las muchedumbres.

Para los Obispos se presenta un dilema angustioso y agobiante: o cumplimos exactamente las mencionadas "ordinationes" en pleno acatamiento y obediencia a la Sede Apostólica y vemos disminuir nuestras escasas vocaciones $Y$ alargarse innecesariamente el periodo de estudios con el alarmante abandono de nuestros feligreses, que por falta de atención sacerdotal son fácil presa del comunismo (ahora más influyente a través de la versión latinoamericana que es el castrismo) y del protestantismo, o pedimos que se nos declare territorio de misión sujeto a la Sagrada Congregación de Propaganda.

Para un estudioso del Derecho -dedicado durante más de veinte años al Derecho romano, con incursiones en el canónico-y al mismo tiem. po Pastor, por disposición de la Santa Sede, de un amplio territorio de alrededor de $15,000 \mathrm{kms}^{2}$ con una población de 419,000 habitantes y sólo 37 sacerdotes, o peor aún _pues deducimos los residentes en las ciudades_- 
para 337,000 campesinos sólo cuenta con 15 sacerdotes (3 de ellos mayores de 60 años), la angustia es grande $y$ humanamente no encuentra solución.

$$
* * *
$$

Para darse cuenta de la realidad de este contingente no es suficiente leer fríos informes $y$ estadísticas aparentes, recluidos en sus gabinetes de trabajo, o asistir a congresos y asambleas que no producen frutos o visitar "oficialmente" las capitales diocesanas, sino lanzarse por los polvorientos, largos, sinuosos y peligrosos caminos de los Ândes, conversar con los abandonados curas y escuchar las lastimeras solicitudes de los pueblos que reclaman al sacerdote que no ven hace años y a pesar de ello conservan su fe tradicionalmente o de las almas piadosas que sollozan porque hace mós de cuatro meses -en un pueblo importante- no reciben $\alpha$ Jesús en la Eucaristía porque no hay sacerdote que celebre la Santa Misa.

Las líneas anteriores han sido redactadas para encontrar teólogos Y canonistas que, como los primeros misioneros discípulos de los insignes maestros dominicos de Salamanca: Soto, Vitoria, Cano, etc. o de los sabios jesuítas del Concilio de Trento, con fina sensibilidad de la situación compleja del catolicismo en este continente, estructuren una legislación adecuada para estos pueblos, desechando lo accidental y permaneciendo fieles a los grandes principios de la Iglesia.

\section{† JOSE DAMMERT BELLIDO Obispo de Cajamarca}

\footnotetext{
NOTA DE LA REDACCION.-Reproducimos este artículo con especial alitorizacisa je su qutor.-Fue publicado anteriormente en la Revista Españoia de Derecho Canćnico (Vol. XVII - N 50 ).

El Excmo. y Revdmo. Monseñor José Dammert Bellido es Doctor en Derecho. Fué Catedrático Titular de Derecho Romano y Catedrático de Derecho Canónico en nuestra Facultad. Ejerció durante muchos años el aargo de Secretario General de la Universidad Católica cuyo Vice-Rectorado desempeñaba al ser designado Obispo curiliar Y Vicario General de la Atquidiócesis de Lima. Es cctualmente Obispo de Cajamarca.
} 